\title{
Effects of radiofrequency on muscle tissue regeneration
}

\author{
Rodrigo Marcel Valentim da Silva ${ }^{1}$, Rafael Limeira Cavalcanti ${ }^{1}$, Bruno Felipe Soares Félix ${ }^{2}$, Rodney \\ Wordnei Coutinho Santos², Tamara Martins da Cunha1', Oscar Ariel Ronzio ${ }^{3}$, Patrícia Froes Meyer ${ }^{2}$.
}

${ }^{1}$ Universidade Federal do Rio Grande do Norte, Natal (RN), Brazil; ${ }^{2}$ Universidade Potiguar, Natal (RN), Brazil; ${ }^{3}$ Universidad Morón, Morón, Buenos Aires, Argentina.

\begin{abstract}
Background: Radiofrequency (RF) is recommended to treat pathologies with the presence of inflammation, as it induces diathermy and, consequently, promotes better oxygenation, nutrition and local vasodilation. Objective: Evaluate the effect of RF on muscle regeneration in Wistar rats. Methods: It is a controlled and randomized experiment, with a sample composed of 40 Wistar rats, divided equally into four groups: G1 (control group), G2 (lesion, without RF), G3 (RF after 72 hours of lesion) and G4 (RF after 7 days of lesion), all sacrificed 21 days after the injury. The RF parameters used were: Sine wave; frequency of $0.5 \mathrm{MHz} ; 5 \mathrm{~cm}^{2}$ treat ment area on the region around the lesion; power of 45\%; two-minute application; intensity of 15 seconds to heat the head, 1 minute at $20 \%$ and another minute at $10 \%$. An optical microscope was used for histological analysis and, for the biomechanical properties (maximum elongation and maximum load), the mechanical traction test of the gastrocnemius muscles. For statistical analysis, the two-way ANOVA test and the Benferroni test were used, considering $5 \%$ of significance. Results: It was observed in G3 that the inflammatory process was optimized by the RF when compared to the other groups, presenting intact muscle fibers with a discreet regeneration process. G4, on the other hand, revealed intense inflammation with significant granulation tissue, as well as fibrosis and healing. As for the biomechanical characteristics, there were no statistically significant differences in the intergroup comparison. Conclusion: RF was more effective when applied after 72 hours after the injury, in addition to not interfering with muscle biomechanical characteristics.
\end{abstract}

Keywords: Diathermy; Regeneration; Skeletal Muscle; Physiotherapy.

\section{BACKGROUND}

Currently, both professional athletes and physically active people are prone to suffer muscle injuries, which can be due to direct trauma, such as lacerations and bruises, and indirect, such as ischemia and distension ${ }^{(1,2)}$. The incidences of muscle injuries increase with age, but the physiological mechanisms of repair remain ${ }^{(2,3)}$.

The muscle repair process occurs in four stages: degeneration, inflammation, remodeling and regeneration. Degeneration occurs in the first hours after the injury, characterized by disorders of myofilament, sarcolemas and cell necrosis. Then, the inflammatory stage begins, marked by the presence of neutrophils, macrophages and stimulation of cytokine production, which activate local satellite cells ${ }^{(4)}$. During the remodeling and regeneration phase, the extracellular matrix matures and organizes, evidenced from 21 days post-injury, in which the muscle is almost completely regenerated ${ }^{(2,5)}$.

The success of muscle repair depends on the nature and extent of the injuries. However, external factors, such as physical therapy treatment, can accelerate the regeneration process, restoring function more quickly ${ }^{(5,6)}$. Thus, there is a range of features of electrothermal phototherapy that can enhance tissue repair. Among these devices, radiofrequency (RF) stands out, which emits electrical currents with frequency between $30 \mathrm{KHz}$ and $300 \mathrm{MHz}$, promoting heat in the deeper tissues ${ }^{17-}$ 9). RF is indicated to treat pathologies characterized by degeneration, inflammation and pain ${ }^{(10-12)}$. Because it causes a thermal effect, it generates vasodilation and increases local irrigation, resulting in better oxygenation and tissue nutrition ${ }^{(1,11,13,14)}$.

The physiological effects associated with RF are the induction of collagen denaturation, resulting in neocolagenogenesis, and the reduction of edema and fibrosis ${ }^{(15-18)}$. However, its implications for the treatment of muscle injuries still have little evidence reported in the scientific literature.

In this sense, for a better understanding of these possible effects, the aim of our study was to evaluate whether RF therapy is able to influence the tissue regeneration process, based on muscle damage induced in Wistar rats.

\section{METHODS}

This is an experimental, pre-clinical, controlled and randomized study. This research was duly approved by the Ethics and Research Committee of the Universidade Potiguar, in the category of studies with animals, with protocol number 312/2010. 
The sample consisted of 40 Wistar (Rattus norvegicos albinus) rats, selected at random, weighing between 250 and $350 \mathrm{~g}$. The animals originated in the Vivarium of the Universidade Potiguar (Natal, Rio Grande do Norte, Brazil), and went through a period of adaptation to the environment for five days, receiving water and food ad libitum.

The animals were divided into four groups, consisting of 10 rats each: control group (G1), group 2 (G2), group 3 (G3) and group 4 (G4). With the exception of $G 1$, all other groups underwent cryolysis in the muscular belly region of the left and right gastrocnemius, due to their important biomechanical function and power, as well as their high incidence of injuries ${ }^{(3,19)}$. Initially, the animals were previously anesthetized using Zoletil $50 \AA$, with a dosage of $0.2 \mathrm{ml}$ per $100 \mathrm{~g}$ and intramuscular administration. After establishing the anesthetic effect (approximately 15 minutes), bilateral trichotomy of the hind legs was performed, followed by asepsis of the region with $2 \%$ Chlorhexidine Digluconate.

Then, a carbon steel scalpel blade (No. 15) was used to make the incision in the animals' skin, approximately $1 \mathrm{~cm}$ deep. Subsequently, the injury was induced by freezing, using an iron rod $(6 \mathrm{~mm}$ wide and $30 \mathrm{~mm}$ long), immersed in liquid nitrogen (N2) for 15 seconds, at a temperature of approximately $-196^{\circ} \mathrm{C}$. Immediately after the immersion, the rod was pressed perpendicularly to the muscular belly for 10 seconds. The procedure was repeated twice, with an interval of 15 seconds between each repetition. Soon after, the skin was sutured using a 3-0 Dental silk thread, with a triangular cutting needle MT17 $-1.7 \mathrm{~cm}$.

The procedures in each group were as follows: G1 was not submitted to any intervention; the G2 was submitted to the injury, but did not receive treatment with $R F$; $G 3$ and $G 4$ received RF application, respectively, 72 hours and seven days after lesion induction. In the groups in which the RF was applied, the treatment was performed three times a week, for a total of 21 days. The parameters used in the RF were: Sine wave; frequency of $0.5 \mathrm{MHz}$; treatment area of $5 \mathrm{~cm}^{2}$, on the region around the lesions; power of $45 \%$; twominute application time; 15 seconds intensity, to heat the head; one minute at $20 \%$ intensity and one minute at $10 \%$ intensity. When 21 days postinjury were counted, the animals were sacrificed in a carbon dioxide $\left(\mathrm{CO}_{2}\right)$ gas chamber.

Then, dissection of the left and right gastrocnemius muscles was performed, the first being used for histological analysis (HA) and the second for the mechanical traction test (EMT). To prepare the slides, each muscle fragment was immersed in $10 \%$ formaldehyde and sent to the Histology laboratory, where it was kept for 24 hours.

After this procedure, the pieces were dehydrated through three passes through alcohol, lasting one hour each. Then, the diaphanization phase was carried out, through three passes through $X y l o \mid \circledast$, for 10 minutes each. Then, the inclusion process was started, by immersing the biological tissue in paraffin heated to $65^{\circ} \mathrm{C}$, in three one-hour passes for each fragment. After hardening of the paraffin, the fragment was taken to the microtome and cut into strips of three to five microns thick. The tapes were placed in a water bath with water at $35^{\circ} \mathrm{C}$, for attachment to the slide.

Once ready, the slides were placed in the oven at a temperature of $65^{\circ} \mathrm{C}$ for drying, followed by the process of staining with Hemotoxiline and Eosin (HE), to identify the morphological changes resulting from the inflammatory process and collagen fibers (blue staining). After this process, the slides were examined by three pathologists, blindly, under an optical microscope (Olympus) and through microphotographs made with a digital camera attached to the microscope, in increments of 40x, 100x and 400x.

To perform the EMT, it was used the universal testing machine SHIMADZU AUTOGRAPH® (model AG-I 50kN), equipped with a load cell with a capacity of $50 \mathrm{kN} / 5000 \mathrm{kgf}$. Two accessories were used, one attached to the load cell and the other to the mechanical press, suitable for fixing the paw to the machine. The femur and the calcaneal region of the animals were fixed, maintaining the knee and ankle at $90^{\circ}$ of angulation.

Thereafter, a $200 \mathrm{~g}$ preload was applied, during an accommodation time of 30 seconds. Then, the EMT continued for eight minutes, with a speed of $10 \mathrm{~mm} /$ minute. The applied load was registered by the TRAPEZIUM software, at regular stretching intervals, generating a graph of the load versus the stretching, until the moment when the muscle broke its fibers. Biomechanical variables were obtained: maximum load (CM), measured in Newtons (N), and maximum elongation (AM), represented in millimeters $(\mathrm{mm})$.

For statistical analysis, the SPSS 19.0 software was used, with the variables expressed as means and standard deviation (SD). Data distribution was analyzed using the KolmogorovSmirnov normality test. To compare the variables between the groups, the two-way ANOVA test with Bonferroni's post hoc was used, with a significance level of $5 \%$. 


\section{RESULTS}

There was a sample loss of five animals during the experimental procedure, in three groups: $\mathrm{G} 2(\mathrm{n}=2), \mathrm{G} 3(\mathrm{n}=2)$ and $\mathrm{G} 4(\mathrm{n}=1)$. However, this loss did not compromise the qualitative and quantitative analyzes of $\mathrm{AH}$ and EMT. With regard to G1, Table 1 presents the histological results obtained, showing the absence of characteristics of the inflammatory process and showing intact muscle fibers in
$100 \%$ of the sample. As for the microscopic analysis, fibers arranged in an organized and aligned manner were observed, with the presence of a thin layer of perimysium around the muscle bundles, as shown in Figure 1. The G1 findings were used as a normal parameter for comparison with the other groups.

Table 1. Histopathological analysis in animals of Group one.

\begin{tabular}{|c|c|c|c|c|c|c|c|c|c|}
\hline \multirow[b]{2}{*}{ Case } & \multicolumn{3}{|c|}{ Muscle Fibers } & \multicolumn{6}{|c|}{ Inflammatory Process } \\
\hline & INT & DEG & REG & $\mathrm{CC}$ & $A G$ & NE & $\mathrm{TG}$ & $\mathrm{COL}$ & TC \\
\hline 1 & +++ & - & - & - & - & - & - & - & - \\
\hline 2 & +++ & - & - & - & - & - & - & - & - \\
\hline 3 & +++ & - & - & - & - & - & - & - & - \\
\hline 4 & +++ & - & - & - & - & - & - & - & - \\
\hline 5 & +++ & - & - & - & - & - & - & - & - \\
\hline 6 & +++ & - & - & - & - & - & - & - & - \\
\hline 7 & +++ & - & - & - & - & - & - & - & - \\
\hline 8 & +++ & - & - & - & - & - & - & - & - \\
\hline 9 & +++ & - & - & - & - & - & - & - & - \\
\hline 10 & +++ & - & - & - & - & - & - & - & - \\
\hline
\end{tabular}

"Note: INT: Integrity; DEG: Degeneration; REG: Regeneration; CC: Chronic; AG: Acute; NE: Necrosis; TG: Granulation tissue; COL: Collagen; TC: Connective tissue.

Figure 1. Microphotography of muscle tissue in Group one
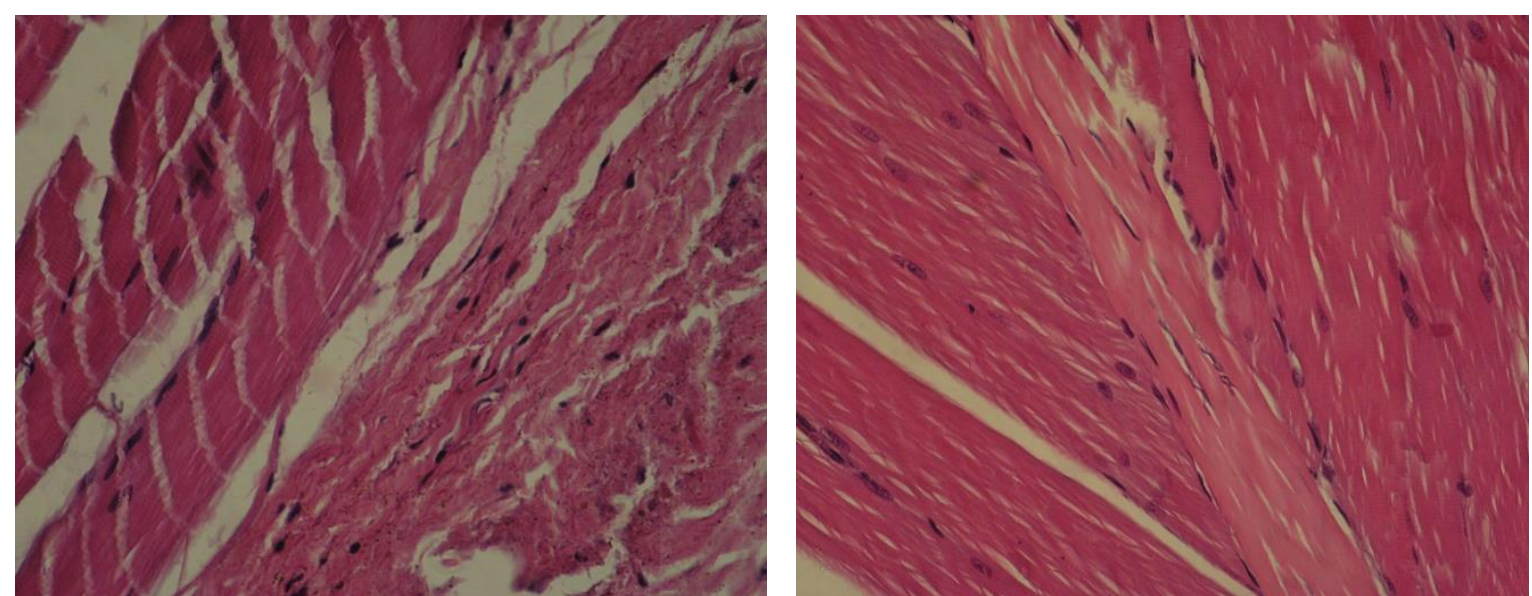

"Note: A: Integral muscular structure and transverse striations (HE 400x); B: Healthy, normal perimysium, showing transverse striations (HE 400x).

The findings in G2, shown in Table 2, point to the presence of intact muscle fibers, with intense degeneration, but with a start of regenerative activity in the muscle tissue. In addition, there was a significant chronic inflammatory process. The presence of edema and inflammatory infiltrate were also observed, with inflammatory cells dispersed in the muscle tissue, as shown in Figure
2. Regarding G3, the results showed healthy muscle fibers, with a slight regeneration process. The inflammatory process in the epimysium was in the chronic phase and, in some animals in the group, the presence of granulation tissue was identified, with an advanced healing process and a low amount of collagen. These results are shown in Table 3 and in Figure 3. 
Radiofrequency on muscle tissue regeneration

Table 2. Histopathological analysis in animals of Group two.

\begin{tabular}{lccccccccc}
\hline \multicolumn{1}{c}{ Muscle Fibers } \\
\hline Case & INT & DEG & REG & CC & AG & NE & TG & COL & Inflammatory Process \\
1 & + & +++ & +++ & ++ & - & - & ++ & ++ & Incipient \\
2 & + & Light- & Light+ & ++ & - & - & ++ & Incipient & INFL+ \\
3 & + & - & - & + & - & - & - & Incipient & INFL+ \\
4 & + & +++ & +++ & + & - & - & ++ & + & INFL+ \\
5 & + & - & - & + & - & - & - & Incipient & INFL \\
6 & + & - & - & + & - & - & ++ & ++ & INFL \\
7 & + & - & - & + & - & - & - & Incipient & EM \\
8 & + & +++ & +++ & ++ & + & - & ++ & ++ & EM
\end{tabular}

'Note: INT: Integrity; DEG: Degeneration; REG: Regeneration; CC: Chronic; AG: Acute; NE: Necrosis; TG: Granulation tissue; COL: Coll agen; TC: Connective tissue; EM: Epimysium; INFL: Inflammatory.

Figure 2. Microphotography of muscle tissue in Group two.

"Note: A: Degeneration and regeneration areas (HE 40x); B: Degeneration and regeneration (HE 100x).

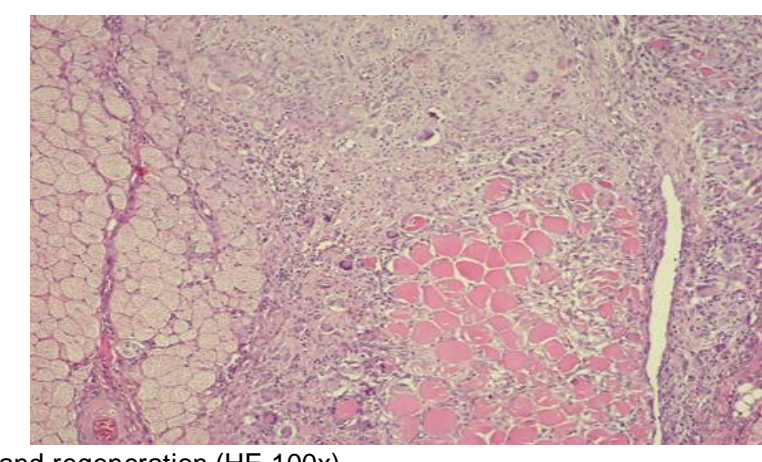

Table 3. Histopathological analysis in animals of Group three.

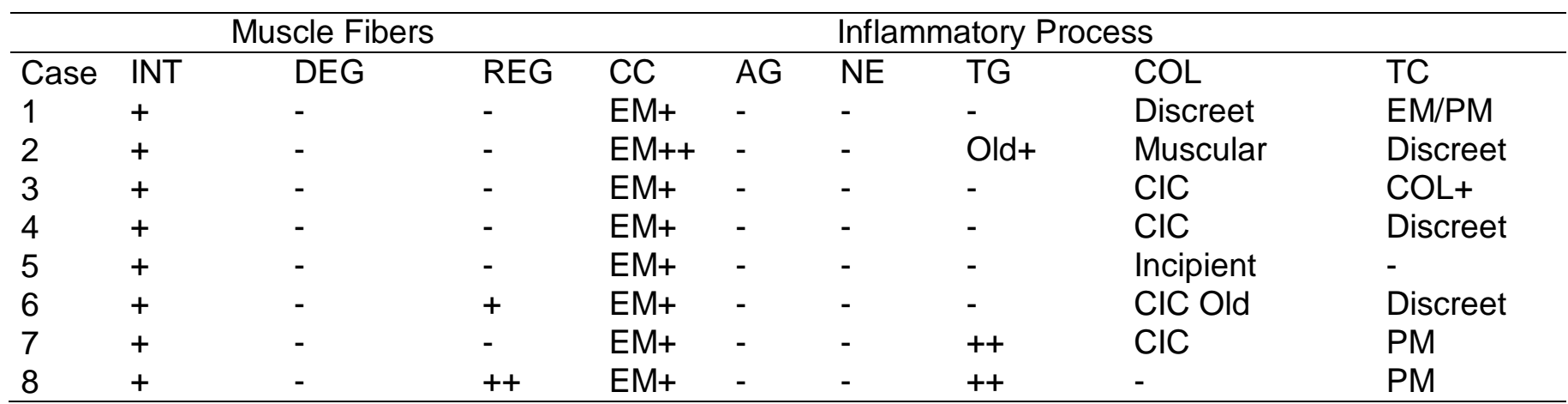

"Note: INT: Integrity; DEG: Degeneration; REG: Regeneration; CC: Chronic; AG: Acute; NE: Necrosis; TG: Granulation tissue; COL: Collagen; TC: Connective tissue; EM: Epimysium; PM: Perimysial.

Figure 3. Microphotography of muscle tissue in Group three.
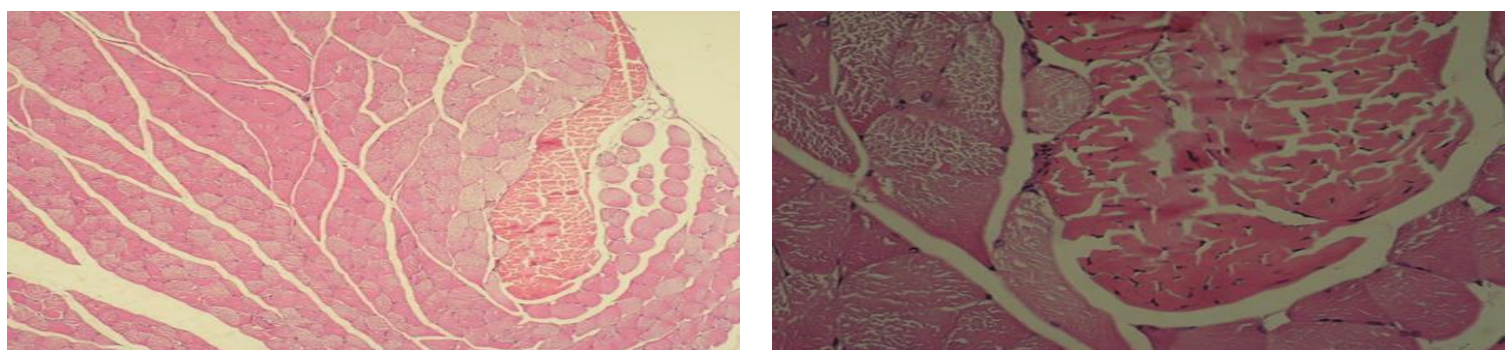

"Note: A: High regenerative activity with intense collagenization of muscle tissue (HE 100x); B: Early healing of the conjunctiva with mature muscle fibrosis (HE 400x). 
In G4, on the other hand, based on the data in Table 4, intense inflammatory reactions were observed, predominantly in the epimysium, and also with some foci in the perimysium. Additionally, there was a significant deposition of young granulation tissue, with fibrosis and advanced muscle healing. These findings can be seen in Figure 4.

Table 4. Histopathological analysis in animals of Group four.

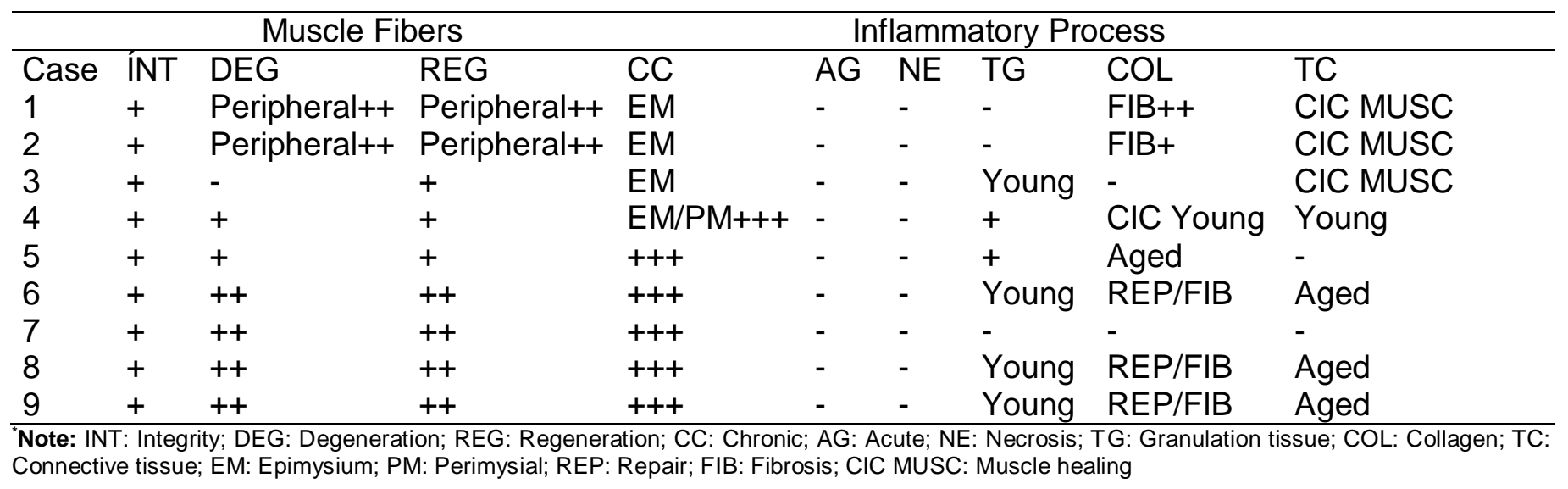

Figure 4. Microphotography of muscle tissue in Group four.
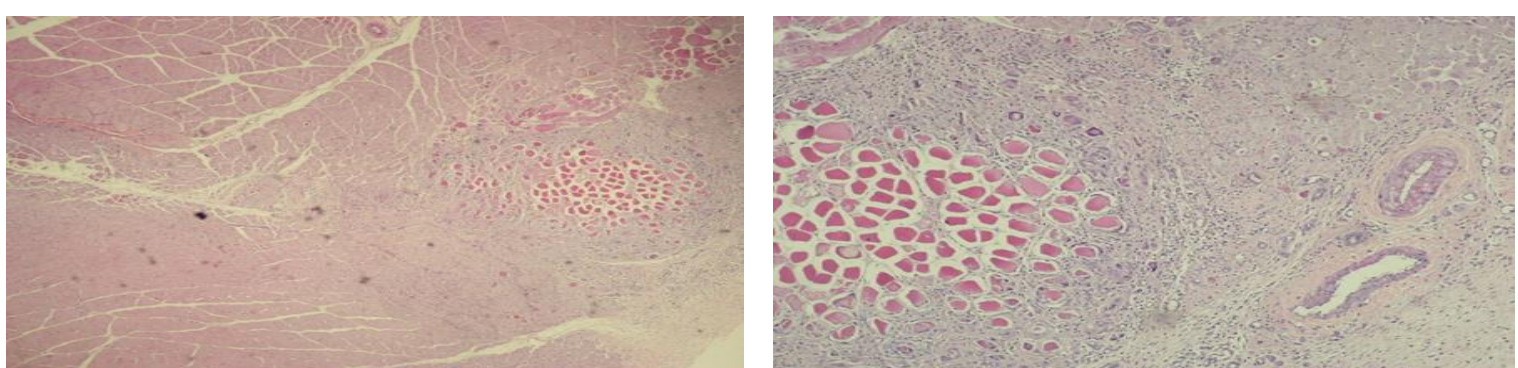

"Note: A: Chronic inflammation of epimysium (HE 40x); B: Deposition of young collagen, with regenerating epimysium (HE 100x).

Finally, in relation to the biomechanical properties of muscle tissue, Figure 5 shows the mean values ( \pm standard deviation) obtained in the EMT, in the four groups. The results obtained from $\mathrm{CM}$ and $\mathrm{BF}$, respectively, were as follows: In G1, 30.18 N ( \pm $6.90)$ and $43.36 \mathrm{~mm}( \pm 10.80)$; In G2, 23N ( \pm 4.31$)$ and 38.05mm ( \pm 9.48$)$; In G3, 28N ( \pm 2.03$)$ and $39.31 \mathrm{~mm}( \pm 11.34)$; and in $\mathrm{G} 4,25.77 \mathrm{~N}( \pm 6.89)$ and $40.20 \mathrm{~mm}( \pm$ 6.20). When comparing muscle biomechanical properties between groups, there was no statistically significant difference, as shown in Table 5.

Table 5. Comparative test between mechanical properties

\begin{tabular}{lllll}
\hline & & Difference & $\mathrm{F}$ & $p$ Valor \\
\hline G1 vs G2 & 7.186 & 2.709 & $>0.05$ \\
CM $(\mathrm{N})$ & G1 vs G3 & 2.178 & 0.8211 & $>0.05$ \\
& G1 vs G4 & 4.415 & 1.718 & $>0.05$ \\
G2 vs G3 & 5.008 & 1.731 & $>0.05$ \\
G1 vs G4 & 2.771 & 1.020 & $>0.05$ \\
AMm) & G3 vs G4 & 2.237 & 0.8234 & $>0.05$ \\
& G1 vs G2 & 5.304 & 1.158 & $>0.05$ \\
G1 vs G3 & 4.052 & 0.8849 & $>0.05$ \\
G1 vs G4 & 3.157 & 0.7117 & $>0.05$ \\
G2 vs G3 & -1.252 & 0.2594 & $>0.05$ \\
& G2 vs G4 & -2.148 & 0.4578 & $>0.05$ \\
& G3 vs G4 & -0.8955 & 0.1909 & $>0.05$
\end{tabular}


Figure 5. Mean values and standard deviations of muscular mechanical properties, in each group.

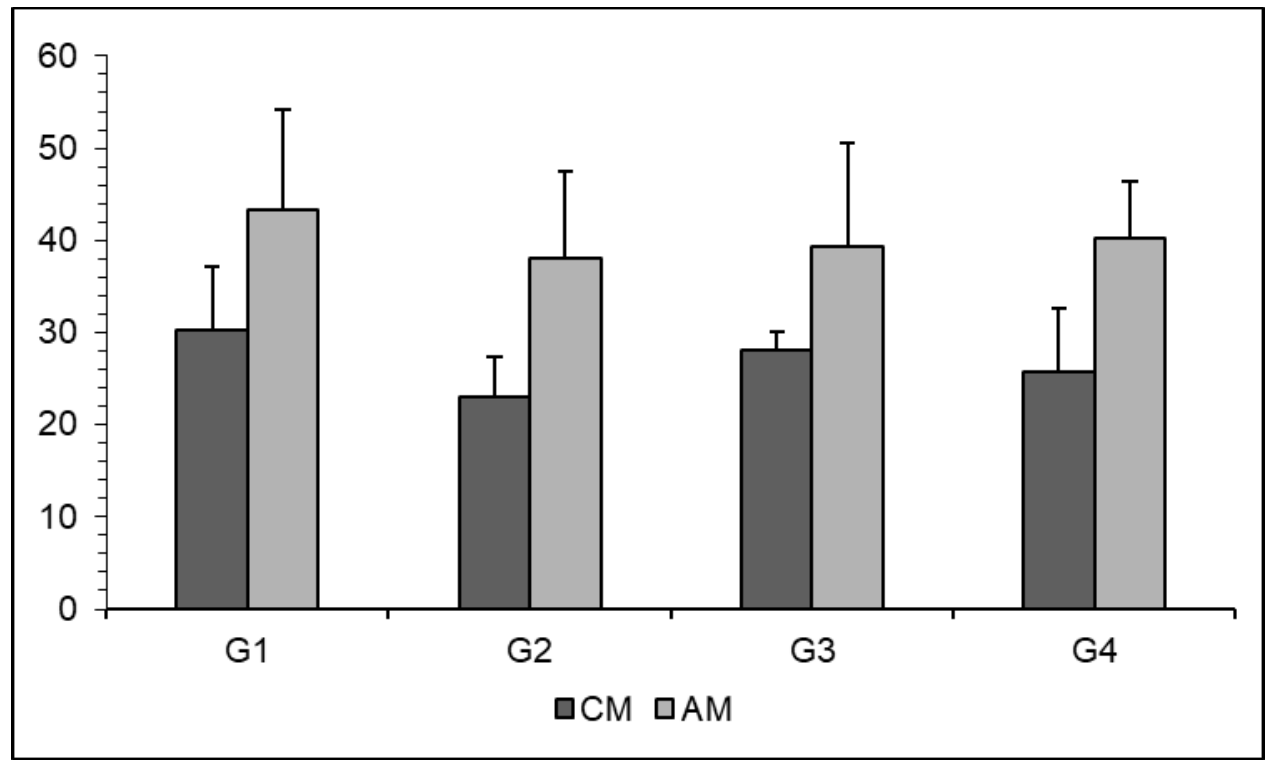

"Note: G1: Control group; G2: Injured animals without treatment; G3: Animals injured and treated after 72 hours; G4: Animals injured with treatment after 7 days; CM: Maximum load in Newtons (N); AM: Maximum elongation in millimeters ( $\mathrm{mm}$ ). Parallel bars correspond to standard deviation.

\section{DISCUSSION}

The present study had the purpose of verifying the possible alterations occurred in the muscular tissue after the application of the RF. Changes corresponding to the condition of the muscle fiber and the situation of the inflammatory process were evaluated, through $\mathrm{HA}$, in addition to the biomechanical properties, such as $\mathrm{CM}$ and $\mathrm{AM}$, assessed at EMT. Based on the results of our study, it was observed that some animals in G3 did not show complete healing of muscle tissue, 21 days after cryolysis. However, it was noticed that there was an important decrease in the signs of inflammatory process after this period, compared to the other groups.

This effect was possibly due to the proinflammatory stimuli promoted by RF, culminating in the acceleration of the tissue repair process ${ }^{(9)}$. A study by Prouza et al. ${ }^{(1)}$, points out that RF therapy acts at the local temperature, causing hyperthermia, which subsequently increases blood circulation, improves oxygen supply and removes activated metabolic waste in the treated area. In addition, RF has been shown to stimulate tissue remodeling through collagen denaturation, causing fiber contraction, which in turn activates fibroblasts and favors neocolagenogenesis ${ }^{(13,1720)}$. These factors may justify the findings found in G3, in which the RF was applied 72 hours after the injury, that is, precisely in the average period of degeneration and acute inflammation.

Evidence suggests that, after injury, there is an increase in reactive oxygen species and circulating muscle damage markers in the bloodstream $^{2}$. It is possible that RF accelerated this process, reducing the latency period of inflammation. Thus, at the end of the repair process, there may have been early healing of connective tissue and a high regenerative activity.

Regarding G4, in which RF was applied seven days after the injury, the presence of inflammatory signs in muscle tissue was found in most animals, with deposition of granulation tissue and some points of fibrosis. The increase in the amount of granulation tissue may be related to an increase in the inflammatory response, due to the chronicity of the inflammation. Consequently, there was a progression of fibroblastic activity and collagen deposition, culminating in the formation of fibrosis. Our finding can be justified by similar data, found in the study of Carvalho et al. ${ }^{(9)}$, who analyzed the effects of RF on the collagen tissue of Wistar rats, also resulting in excessive collagen deposition.

Another important factor is that, unlike the results found in G3, this finding suggests that $R F$ appears to be less effective when applied in the later stages of tissue inflammation, since the effects described above occurred in a smaller proportion. This may have occurred due to the lower number of RF applications in G4, which may have been insufficient to cause acceleration in the regeneration and healing of muscle tissue.

With regard to the variables analyzed in the animals' gastrocnemius muscles, the $\mathrm{CM}$ and the 
AM did not show statistically significant differences between the groups. This suggests that RF does not interfere with muscle biomechanical properties, keeping them thus preserved when compared to control groups.

These results converge with the existing evidence, which justifies that the biomechanical particularities can be influenced by changes in muscle tissue ${ }^{(21)}$. However, there is a similarity found in the values obtained between the groups of our research, which suggests two hypotheses. In the first, there is the hypothesis that, possibly, cryolysis did not compromise the biomechanical properties of the muscle. And in the second, it is suggested that the release of the animals throughout the study protocol, allowed normal movement of the limbs and, therefore, there was a structural restoration in the function of the muscles.

Thus, the resting position adopted by the animals would cause a tension stimulus, generating a response similar to the muscle stretching technique. According to the study of Polizello et al. ${ }^{(21)}$, during EMT, the tensile strength is directly related to titin, a protein that acts on the natural passive resistance of skeletal muscle. Thus, this stimulus may have been able to maintain the musculoskeletal mechanical properties, decreasing passive resistance and increasing tissue viscoelasticity. The present study had some limitations, which must be considered: The nonuse of more accurate instruments for quantitative assessment in histological analysis, as well as the absence of an immunohistochemical analysis of muscle tissue.

\section{CONCLUSION}

In summary, the results of our study indicate that RF therapy, in the parameters used, was able to generate pro-inflammatory effects and accelerate the regenerative process in the muscle tissue of Wistar rats. It was also shown that RF was more effective when applied 72 hours after the injury, in the acute phase of the inflammatory process. However, this intervention did not alter the biomechanical muscle characteristics in the animals' gastrocnemius. Thus, it is possible that RF is an effective therapeutic resource for the rehabilitation of muscle injuries in humans. Thus, we suggest the development of new research involving the application of this treatment in musculoskeletal disorders, using assessment instruments considered to be the gold standard, and testing other application parameters.
Author's contribution: To carry out this study, each author contributed individually and significantly to the development of this article, as described below: RMVS participation in the entire intellectual concept of the study, and in the analysis of histological data and biomechanical properties of the muscle tissue of animals. RLC writing and review of the article, with participation in the entire intellectual concept of it. BFSF literature review, elaboration of the research project and participation in the gastrocnemius tendon removal surgery of the animals. RWCS literature review, elaboration of the research project and participation in the gastrocnemius tendon removal surgery of the animals. TMC writing and review of the article. OAR analysis and treatment of research data. PFM performing the gastrocnemius tendon removal surgery of the animals, and participating in the analysis of the histological data of the muscle tissue.

Financial support: Nothing to declare.

Conflict of interest: The authors declare that they have no conflict of interest.

\section{REFERENCES}

1. Prouza O, Gonzalez A. Targeted Radiofrequency Therapy for Training Induced Muscle Fatigue - Effective or Not?. Int J Physiother. 2016;3(6):707-10.

2. Silveira P, Victor E, Schefer D, Silva L, Streck E, Paula M, et al. Effects of Therapeutic Pulsed Ultrasound and Dimethylsulfoxide (DMSO) Phonophoresis on Parameters of Oxidative Stress in Traumatized Muscle. Ultrasound Med Biol. 2010;36(1):44-50.

3. Ekstrand J, Hägglund $M$, Waldén $M$. Epidemiology of Muscle Injuries in Professional Football (Soccer). Am J Sports Med. 2011;39(6):1226-1232.

4. Souza A, Morete M. O uso da radiofrequência pulsátil no tratamento da dor lombar. Rev Dor. 2012;13(2):165-9.

5. Pertille A, Moura K, Matsumura C, Ferretti R, Ramos D, Petrini A, et al. Evaluation of skeletal muscle regeneration in experimental model after malnutrition. Braz J Biol. 2017;77(1):8391.

6. Pertille A, Macedo A, Oliveira C. Avaliação da regeneração muscular em animais idosos após tratamento com laser de baixa intensidade. Rev Bras Fisioter. 2012;16(6):495-501.

7. Osti R, Pari C, Salvatori G, Massari L. Trilength laser therapy associated to tecar therapy in the treatment of low-back pain in adults: a preliminary report of a prospective case series. Lasers Med Sci. 2014;30(1):407412.

8. Masala S, Fiori R, Raguso M, Ojango C, Morini $M$, Cuzzolino $A$, et al. Pulse-Dose 
Radiofrequency in Athletic Pubalgia: Preliminary Results. J Sport rehabil. 2017;26(3):227-233.

9. Carvalho G, Filho JM, Meyer P, Ronzio O, Medeiros J, Nóbrega $M$, et al. Avaliação dos efeitos da radiofrequência no tecido conjuntivo. Rev Bras Med. 2011;68:10-25.

10. Vas L, Khandagale N, Pai R. Successful Management of Chronic Postsurgical Pain Following Total Knee Replacement. Pain Medicine. 2014;15:781-1785.

11. Ronzio O, Fonseca AS, Filho SS, Filho MB. Cellular and molecular effects of electromagnetic radiation and sonic waves. S Afri J Sci. 2013;109(7/8):1-4.

12. Lakemeier $S$, Lind $M$, Schultz $W$, FuchsWinkelmann S, Timmesfeld N, Foelsch C, et al. A Comparison of Intraarticular Lumbar Facet Joint Steroid Injections and Lumbar Facet Joint Radiofrequency Denervation in the Treatment of Low Back Pain. Anesth Analg. 2013;117(1):228-235.

13. Simmons B, Griffith R, Falto-Aizpurua L, Nouri $\mathrm{K}$. Use of radiofrequency in cosmetic dermatology: focus on nonablative treatment of acne scars. Clin Cosmet Investig Dermatol. 2014;7:335-39.

14. Masala $S$, Fiori $R$, Raguso $M$, Morini $M$, Calabria E, Simonetti G. Pulse-Dose Radiofrequency for Knee Osteoartrithis. Cardio Vasc Intervent Radiol. 2013;37(2):482-487.

15. Adatto M, Adatto-Neilson R, Morren G. Reduction in adipose tissue volume using a new high-power radiofrequency technology combined with infrared light and mechanical manipulation for body contouring. Lasers Med Sci. 2014;29(5):1627-1631.

16. Silva RV, Barichello $P$, Medeiros M, Mendonça W, Dantas J, Ronzio O, et al. Effect of Capacitive Radiofrequency on the Fibrosis of Patients with Cellulite. Dermatol Res Pract. 2013;2013:715829.

17. Choi S, Shin JH, Nam SW, Jang H, Tao T, Kwak HW, et al. Mid-long term effect of nonablative high radiofrequency therapy on the rabbit dermal extracellular matrix. Annu Int Conf IEEE Eng Med Biol Soc. 2013;2013:3761-4.

18. Lolis M, Goldberg D. Radiofrequency in Cosmetic Dermatology: A Review. Dermatol Surg. 2012;38(11):1765-1776.

19. Hwang C. Excessive Gastrocnemius Fibrosis Developed After Radiofrequency-Induced Cosmetic Volume Reduction. Aesth Plast Surg. 2011;35(6):1172-1175.
20. El-Domyati M, El-Ammawi T, Medhat W, Moawad O, Brennan D, Mahoney $M$, et al. Radiofrequency facial rejuvenation: Evidencebased effect. J Am Acad Dermato. 2011;64(3):524-535.

21. Polizello J, Carvalho L, Freitas F, Padula N, Shimano A, Mattiello-Sverzut A. Propriedades Mecânicas do Músculo Gastrocnêmio de Ratas, Imobilizado e Posteriormente Submetido a Diferentes Protocolos de Alongamento. Rev Bras Med Esporte. 2009;5(3):195-99. 